\title{
Teacher Retention and Quality Education: Impact of Rural Incentives in North-West, South Africa
}

\author{
Poti, Joyce G. \\ North-West Provincial Government, Mafikeng, SA. \\ gpoti@nwpg.gov.za \\ Andrew Mutsvangwa \\ North-West University, Mafikeng, SA \\ Andrew.Mutsvangwa@nwu.ac.za \\ Muchativugwa Liberty Hove \\ North-West University, Mafikeng, SA \\ muchativugwahv@gmail.com
}

Doi:10.5901/mjss.2014.v5n27p792

\begin{abstract}
In order to retain current qualified teachers in rural schools, largely in inaccessible areas, since they have the necessary skills and qualifications, a policy on incentives was signed by the education minister and published in the Government Gazette no 30678 on 18 January 2008. Its establishment was because rural areas are characterised by factors that negatively influence delivery of quality education. The problem is that ever since the introduction of the Teachers Rural Incentive Scheme, the latter has never been evaluated to validate its design objectives and projected impact. This article investigated, through an evaluative survey, the impact of rural incentives in retaining teachers and ensuring quality education in the rural schools of the North West Department of Education in South Africa. In an emerging economy such as South Africa, quality education becomes a yardstick for global comparability.
\end{abstract}

Keywords: Attrition, capacitation, Incentive, retention, Rurality , urban spaces

\section{Context}

South Africa's educational system has been under the spotlight from quality assurance bodies and cynics at home who perceive incongruences between vision and reality. Performance of learners in Mathematics and Science subjects in particular has irked both assessors and classroom practitioners. In order to stem this negative tide, many an effort has been invented in order to attract and retain qualified personnel tasked with curriculum delivery.

This article investigated, through an evaluative survey, the role of rural incentives in retaining teachers and ensuring quality education in the rural schools of North West Department of Education, South Africa. Rurality is a big challenge in the North West Province. According to Ditlopo and Blaauw (2010), rurality is inextricably linked to negative factors such as poverty and a general lack of access to basic needs. The poverty that is prevalent in the rural areas of the North West Province has marginalized most of this populace. This marginalization implies exclusion from the available resources in South Africa. Teachers are responsible for providing quality public education in South Africa. Their commitment determines the successful implementation of curriculum and curriculum delivery reforms in schools. Teacher satisfaction has, in turn, been tied to teachers' performance, including teachers' involvement, commitment and motivation on the job (Sargent and Hannum: 2006).

Job dissatisfaction, leading to attrition in the teaching profession, aggravates teacher shortages in rural areas, especially the qualified. A system of incentives for teachers in the rural areas was introduced for them to stay and do work in rural schools. The Teacher Rural Incentive Scheme (TRIS) provides and reduces the educational resource supply and community marginalization gap identified. It was observed that there is a significant percentage of teachers indicating that with or without the system, they would want to relocate to urban schools, given a chance. However, this study suggests that there is a need for the TRIS scheme to be improved in order to accentuate its mediation and motivational 
effect.

\section{Background}

The South African Schools Act, 84 of 1996 (SASA) and various education legislative acts and policy documents say that all South African learners should have access to the same quality of learning and teaching, facilities and educational opportunities. However, despite the hiatus between rural and urban provisions, the Department of Education is determined not to recognise "rural education" as a separate category.

Shortages of qualified teachers lowers the quality of education in poor rural areas. Sargent and Hannum (2006) says in rural China, where certified teachers are difficult to recruit and retain, principals hire substitute or temporary teachers, who generally have lower levels of education and little or no formal teacher training. The more qualified teachers resign, the more it becomes difficult for the department to recruit and retain equally efficient new teachers. In trying to retain the current qualified teachers in rural areas, since they have the necessary skills and qualifications, the policy on incentives was signed by the minister on 15 December 2007 and published in the Government Gazette no 30678 on 18 January 2008.

The policy addressed scarcity of teachers in:-

- Remote and rural areas

- Specific subjects (specifically Mathematics and Science)

- Circumstances that make recruitment difficult

This policy was a part of a wider recruitment and retention strategy aimed at getting the right number and quality of teachers in the system.

Guiding principles of the policy were:-

- Striking a balance between meeting the apparent need and affordability

- Customising the criteria by Provincial Education Department (PED) and prioritizing their own needs and context.

The remoteness and scarcity of subject expertise affected which posts were incentivised.

According to Surty (2011: 9), "the Department of Basic Education realises that there is a need to have a different strategy for rural development and rural education." The Department has consequently established a framework for rural education, given its peculiar character. The rural allowance policy intends to attract and retain teachers to work full-time in public schools in rural, under-serviced, under-resourced and marginalized areas. It was therefore important that the effect of this new allowance was measured in the short term by direct questioning of those receiving the allowance and enable a more direct evaluation of the effect.

\section{Problem Statement}

The problem is that ever since the introduction of the Teachers Rural Incentive Scheme (TRIS), the latter has not been evaluated to validate its design, objectives and projected impact. Its establishment was based on the fact that rural areas are characterised by various factors that negatively influence the delivery of quality education. Many rural communities and their schools are poor and disadvantaged. Limited resources in rural areas often extend to teachers. Rural schools find it difficult to attract qualified and suitable teachers because there are less financial resources and incentives available. For the same reason, it is difficult to retain qualified teachers in rural areas (Surty, 2011). Furthermore, studies indicate that while many countries face challenges of teacher supply, there are equally serious challenges of qualified teacher retention. In many countries there are qualified teachers in urban areas who are unemployed, while there are unfilled posts in rural areas (Mulkeen, 2005). Mulkeen further states that this pattern of simultaneous surplus and shortage is strong evidence that the problem of teachers for rural schools cannot be solved simply by providing and producing more teachers. There is a need for policies that ensure that the teachers reach the schools where they are most needed.

The new TRIS is a national initiative that aims to address this problem. While the effect of the rural allowance may eventually be seen in staffing patterns of rural schools, the long-term effect is likely to be diluted by the many other factors that influence teachers, apart from financial benefits.

This study focused on an evaluative analysis of the implementation and perceived effectiveness of TRIS in retaining qualified teachers to ensure delivery of quality education in the schools of North West Department of Education. 


\section{Research Question}

What measurable impact has been generated by TRIS in recruiting, deploying and retaining qualified teachers in rural areas in the North-West Province in South Africa?

The following sub questions guided this study:

1. Does a rural incentive help rural schools to retain teachers?

2. Are there teachers moving from rural non-incentive schools to incentive schools?

3. Does a rural incentive affect educator attendance?

4. Are schools that get a rural incentive performing better than those that do not get it?

\section{Objectives}

To resolve the primary research question, the following objectives were set:

- To establish whether rural incentives help schools to retain teachers

- To determine if there are teachers moving from non-rural incentive schools to incentive schools

- To establish if the schools that get rural incentives perform better than those that do not, and

- To determine whether rural incentives affect educator attendance.

\section{Conceptual Framework}

The literature review aimed at contributing towards a clearer understanding of the nature and meaning of the problem identified (De Vos, Strydom, Fouche and Delport, 2002:127). According to Schumacher and McMillan (2001:108) literature review adds much to an understanding of the selected problem and helps to place the results of a study in a historical perspective.

\subsection{What do urban and rural mean?}

The terms urban and rural have a complicated history in South Africa. Urban spaces - that is, cities and towns - were, under apartheid, the domain of whites (who also owned $87 \%$ of the country's land). Black workers were re-located into townships (rural) centres. This racial cartography of apartheid insisted that all African people belonged to one "homeland" or another, all of them some distance from urban areas. That was an apartheid instrument used to control the movement and the economic participation of black people. One distressing legacy of this demarcation is that rural areas are still perceived in negative terms since they were grim former homelands. They have remained places which are a trap for the old and the young.

\subsection{What is a rural school?}

A rural school corresponds to geographic isolation, under-resourcedness, under-qualified teaching personnel and small enrolment size. Such schools are often small as identified by local factors, where geographical location can make networking and the delivery of effective pedagogy problematic. The quality of education in rural areas is characterised by several deficiencies. Real quality in education in rural areas can only be buttressed through significant social and economic development. Villages and rural communities are difficult to reach, the physical conditions in schools are inadequate, and learner performance in comparison to schools elsewhere is lower. Although there have been significant infrastructural improvements since 1994, according to the National Education Infrastructure Management System: National Assessment Report (2007), many rural schools still lack clean running water, electricity, libraries, laboratories and computers. More than one quarter of the schools in Eastern Cape, KwaZulu-Natal and Limpopo have more than 45 learners per classroom. These are not conducive conditions in which to provide quality education. The North West Province of South Africa also has more rural schools than urban schools. Of the total 1584 schools, 1226 schools are in rural areas whilst only 358 schools are in urban areas, mostly located in townships.

\subsection{What is rural incentive?}

An incentive motivates an individual to perform an action. The study of incentive structures is central to the study of all 
economic activities (both in terms of individual decision-making and in terms of co-operation and competition within larger institutional structures). Economic analysis, then, of the differences between societies (and between different organizations within a society) largely amounts to characteristics of the incentive structures offered to individuals. Ultimately, incentives aim to provide value for money and contribute to organizational success.

Incentive structures, however, are notoriously trickier than they might appear to people who set them up. The officials offering incentives are often unable to predict all of the ways that recipients respond to them. Thus, imperfect knowledge and unintended consequences often make incentives much more complex than the officials offering them originally expected, and lead either to unexpected windfalls or to implosions produced by unintentionally perverse reactions.

Teacher trade union SADTU in South Africa are still calling on the employer, DoE, to pay incentives to rural teachers. With proper planning and implementation, SADTU are convinced this should address the quality gaps in educational provisions for rural areas. For the purposes of this study, rural incentive is the monetary allowance that the Department of Education gives to teachers in remote, rural schools so at to motivate and retain them.

\subsection{Rural allowance policy}

Some parts of the education system are still lagging far behind others, twenty years after constitutional democracy. Following reports that provincial departments of education are neglecting schools, especially in the far-flung rural areas of the country, a survey was undertaken to establish the distribution of qualified teachers. Getting qualified personnel to teach in the rural schools has been difficult for the employer; this is mostly because of the living conditions obtaining in these rural communities and schools in particular, yet in the past qualified teachers have been lured to the same schools that are being shunned today.

In trying to retain the current teachers at rural areas since they have the necessary skills and qualifications, the policy on incentives was signed by the minister on 15 December 2007 and published in the Government Gazette no 30678 on 18 January 2008. According to Surty (2011), the DoE realises that there is a need to have a different strategy for rural development and rural education. The implementation of TRIS for teachers has been a challenge for the department since its inception in 2008/09. Different factors were considered in identifying schools qualifying for the incentives:-

\subsection{Remoteness of the school}

This variable measures how far a school is situated from the nearest town. Such a town should have basic facilities and services that a teacher would need to have access to. The head of department identified towns in, near or bordering the province and determined the distances by road from each school to the nearest town.

In 2006 the National Department of Education contracted EduAction (Decision Support in Education Consulting cc) to provide professional and technical support to guide the DoE in developing a model for identifying remote schools for the introduction of a national incentive scheme. The intention was to acknowledge the challenges faced by teachers working in remote areas.

\subsection{Classification of towns}

The Terms of Reference for the EduAction project acknowledged that a standard definition of 'rural' was 'complex to formulate in the context of South Africa'. In other words, the notion of a school in a 'rural area' could imply any of a wide range of geographical locations, such as just outside an established urban area, or several hundred kilometres from the nearest town, or in a sparsely populated farming district where some small towns were present. It was therefore decided that the project should focus on 'remote' schools in order to determine which schools qualified for the proposed incentive. This was defined in terms of the distance of a school from the nearest town. Since not all towns offer the same facilities, it was important to distinguish between different sizes of towns since this affects a school's ability to recruit teachers and its attractiveness as a place of work.

The main challenge of the evaluation was therefore classifying 'remote' schools with the qualifying criteria being how far a school is from the nearest town and more specifically what facilities the local town/s provided. Since the nearest town may only provide limited basic facilities it was important to extend the distance calculation to the next higher order town (which may be a large town with more robust services) and further to the nearest metropolitan area (where a significant pool of qualified teachers may exist). The methodology thus involved three distance calculations - to 
metropolitan areas, large towns/cities and small towns.

One of the guiding principles in the project was 'what kinds of services do teachers require when they are redeployed or relocated?' The following are typical necessities:

- Shops to buy food, clothing and household necessities

- Banks

- Places of entertainment

- Health care such as doctors, dentists, clinics and hospitals

- Sizeable and affordable accommodation.

Others, less obvious but important services, might be government facilities such as Home Affairs, Police Stations and Post Offices or household-level service providers such as electricians and plumbers. The project scope and timescales did not allow for a detailed town-by-town survey of available facilities so the pragmatic option was to use datasets that provided reasonably comprehensive details on the location and availability of retail stores, petrol stations, hotels and to supplement this with available data on the distribution of government services and health facilities.

The distance of a school from the nearest town was therefore the main qualifying criterion to determine whether the teachers working at the school would qualify for the proposed rural schools incentive scheme. The three types of towns considered in the distance calculations were:

1. Small towns (Category 3)

2. Large towns / regional service centres (Category 2)

3. Metropolitan areas (Category 1)

\subsection{Small Towns (Category 3)}

To qualify as a 'Small Town', that town should have at least three of the following basic facilities on offer:

(i) Food/Convenience Store (e.g. Spar, Shoprite, Checkers, Diskom)

(ii) Clothing Store (e.g. Pep, Ackerman's)

(iii) Petrol (filling) Station (e.g. BP, Shell, Engen)

(iv) Furniture Store (e.g. Lewis, Russells, Joshua Doore)

(v) Fast food outlet (Kentucky, Wimpy)

Many towns did not meet all five of the above criteria, but had a sufficient number of basic facilities to satisfy 'basic needs' or day-to-day type shopping. A town with just a single food or clothing store normally did not qualify as Category 3 and was designated a Category 4 town.

The presence/absence of a Doctor was not included in the above list of criteria owing to the lack of a reliable national dataset of Medical Practitioners. Similarly, the presence/absence of a bank was not included due to confidentiality problems with data on financial institutions. The existence of hospitals and/or clinics was however taken into consideration, particularly in defining Category 2 (large) towns.

\subsection{Large Towns / Regional Service Centres (Category 2)}

Qualifying criteria for a Large Town / Regional Service Centre was that it should contain all the facilities found in a Small Town but in much greater frequency and variety. A Large Town / Regional Service Centre should also have larger and more specialist retailers such as Pick'nPay, car dealerships, recreational facilities as well as a wide variety of restaurants.

The criteria for a town to qualify as a 'Large town / Regional Service Centre' were therefore all the criteria that apply for Small Towns, plus:

(i) One or more Government service offices

(ii) Recreational facilities such as Movie Theatres, Sports Clubs/Gyms and Golf courses, two or more medical facilities such a Pharmacy, a Medical Centre, clinic or hospital

(iii) At least one 'signature' food retailer such as Pick 'n Pay, Woolworths, Hyperama

(iv) Several automotive facility stores such as car dealerships, tyre/exhaust repair, part dealers such as Midas, Trentyre, Mazda, Ford, BMW.

A further two types of towns were classified, but not used in the distance calculations, namely:

(i) Small towns with insufficient services (Category 4)

(ii) Very small towns/villages or settlements.

Once the range of facilities had been decided upon, towns were classified and the process of calculating the 
proximity of schools from them was undertaken. In this way, a scheme of incremental incentives for teachers could be considered, ranging from 'metropolitan area' school (where no incentive would apply) to 'deep rural' schools, (which would attract the maximum incentive) in the NW province.

\subsection{Datasets used}

Several important datasets were used in the analysis, each of which is briefly described below:

Schools (approximately 28,640 points) - this point dataset was provided by the National Department of Education's EMIS section. The schools database included the school coordinates (latitude \& longitude readings), as well as the postal and physical address, sector, phase and owner of the school and the number of teachers and learners.

Cities/towns/suburbs/settlements/villages (1,127 defined areas) - this dataset provided an extensive polygon coverage defining the location of all settled areas in South Africa, ranging from large cities to towns to small villages and communal centres. The dataset consisted of official legislated metropolitan areas, designated large towns as well as smaller urban areas, rural settlements and hamlets.

Facilities $(63,857$ points) - this key dataset provided information on the range of facilities and services in towns. Facilities such as accommodation, filling stations, financial institutions, retail stores, tourism attractions and medical facilities were included as well as police stations, schools and government service infrastructure.

Road Networks (57, 429 road segments) - this line-based dataset enabled the calculation of distances by road from schools and the three defined categories of towns. The road distance was calculated using Network Analysis and provided a much more accurate assessment of distances to towns and their services from schools than a conventional straight-line distance calculation. Distances to towns were calculated irrespective of whether the nearest town and school were in the same province or not.

\subsection{The benefits of rural schools to their communities}

Rural schools provide their communities with many benefits. One definition of social capital is, "the aggregate of the actual or potential resources which are linked to possession of a durable network to membership in a group which provides each of its members with the backing of the collectively-owned capital." The support contributed by small, rural schools to students and the wider community can overcome shortages of social capital (Howley \& Harmon, 2000). The small classroom sizes of many rural schools can account for any differences in educational achievement between rural schools and their urban counterparts. According to Barley \& Beesley (2007), one effect of small schools is that students in poor rural areas do better academically on average than students in poor urban areas. Rural schools are also more likely to provide safer atmospheres for their lower-income students than urban schools according to Suski (2007) as cited by Hall (2007).

According to Hall (2007), in addition to the above benefits of rural schools, students from rural schools are more likely to state that they are more content with their school, which of their teachers are more accommodating, and they feel safer, compared with urban students. According to Barley \& Beesley (2007), the small communities in which a great portion of these schools exist also benefit their schools by providing better community support, often acting as a community centre in their districts. Rural schools contribute toward more democratic inclusion, a greater ability to overcome the effects of poverty, and they also make their communities more susceptible to positive social change by providing feelings of community. Hall (2007) further states that quality rural schools are a necessity in order for the economy and government to flourish. All of these benefits demonstrate the importance of rural schools to their communities and the region in which they exist. Children, families and other residents of rural areas benefit greatly from their schools.

\section{Teacher Recruitment and Retention}

In examining recruitment and retention of teachers in rural areas, David Monk (2007) begins by noting the numerous characteristics of rural communities-small size, sparse settlement, distance from population concentrations, and an economic reliance on agricultural industries that are increasingly using seasonal and immigrant workers. Many, though not all, rural areas, he says, are seriously impoverished. According to Monk (2007), classes in rural schools are relatively small, and teachers tend to report satisfaction with their work environments and have relatively few problems with discipline but teacher turnover is often high, and hiring can be difficult. 


\section{Incentives for Teachers in other Countries}

Some countries have attempted to make working in rural areas more attractive through the use of incentives: a hardship allowance, travel allowance, or subsidised housing. In other areas the incentives may be non-monetary, including, for example, special study leave and further training opportunities (Gaynor, 1998, p17; Craig, Kraft \& Plessis, 1998).

In Mozambique, there is a system of financial bonuses for teachers who locate in rural areas. Schools are classified into four location categories, ranging from urban schools to the most isolated schools, and teachers are paid a salary bonus depending on the location of the school. Although the bonus payments appear attractive, they are weakened by two factors: First, the payment depends on both location and on teacher qualification. For the teachers with low qualifications (the bulk of primary teachers) there is no bonus at all. For teachers with a mid-level qualification (N3, IMAP qualification), the difference between teaching in a provincial town and a remote school is relatively small (only $14 \%$ of salary). Second, teachers who teach two shifts receive a bonus of $60 \%$ of their basic salary. Two shift schools are found more frequently in the areas of a high population density, and so teachers in towns and cities are more likely to have the option of additional earnings from this source.

In Lesotho there is a hardship allowance paid as a flat fee of M275 per month. This is equivalent to $20 \%$ of salary for an unqualified teacher, but only $10 \%$ of salary for a teacher with a diploma qualification. This is generally acknowledged to be too small to encourage the more highly qualified teachers to locate in remote areas.

Table 1: Incentives to encourage Teacher Retention in Rural Areas

\begin{tabular}{|c|c|c|c|c|c|}
\hline & Mozambique & Lesotho & Malawi & Uganda & Tanzania \\
\hline $\begin{array}{l}\text { Rural Area } \\
\text { Incentives }\end{array}$ & $\begin{array}{l}\text { Bonus payments up to } 100 \% \text { of } \\
\text { salary. But only to highly } \\
\text { qualified teachers. Most primary } \\
\text { teachers do not get any } \\
\text { additional payment to move to } \\
\text { rural areas. }\end{array}$ & $\begin{array}{l}\text { A flat bonus of } \\
275 \text { Maloti ( } 47 \\
\text { USD) per month } \\
\text { to locate in a } \\
\text { mountain area. }\end{array}$ & $\begin{array}{l}\text { No incentives } \\
\text { currently for locating } \\
\text { in rural areas, } \\
\text { possibilities being } \\
\text { considered } \\
\text { EMIS data shows } \\
\text { strong correlation } \\
\text { between housing \& } \\
\text { female teachers }\end{array}$ & $\begin{array}{l}\text { In 2001, introduced a } \\
\text { hardship allowance of } \\
20 \% \text { of salary for 'hard- } \\
\text { to-reach' areas. Only } \\
\text { qualified teachers are } \\
\text { eligible } \\
\text { There have been } \\
\text { difficulties in deciding } \\
\text { which are hard to reach } \\
\text { schools. }\end{array}$ & $\begin{array}{l}\text { None at present - } \\
\text { used to have one in } \\
\text { the } 80 \text { s but abolished } \\
\text { in } 90 \text { s. } \\
\text { PEDP stated priority } \\
\text { to rural teacher } \\
\text { housing, but in } \\
\text { practice not } \\
\text { implemented }\end{array}$ \\
\hline
\end{tabular}

These cases highlight two lessons concerning the use of incentives. First, the incentives need to be substantial to outweigh the social and economic costs of living in an isolated area. Second, incentive systems require a fair system of classification of schools. General classifications may provide bonuses to teachers working in small towns, while doing relatively little to increase the qualified teacher supply in the most isolated schools.

Finally, incentive schemes can be outweighed by counter-incentives from urban schools. In Mozambique, urban schools are more likely to offer two-shift teaching, which carries a salary bonus. In other countries, schools in richer communities are able to raise money from parents through voluntary contributions or parent teacher associations. These extra resources can be used to provide additional benefits, or even additional salary, for teachers.

\section{Research Design}

Cohen, Manion and Morrison (2000), argue that in planning research it is important to distinguish between methodology and methods, approaches and instruments, styles of research and ways of collecting data. De Vos (2007:358) explains a research methodology as a diligent and systematic enquiry of a phenomenon to discover facts and theories. The population sample is described and the participant selection process is explained. The methods used for distribution and collection of the survey are discussed. Statistical treatments of the survey data are outlined.

Mouton (2001: 55) says research design is a blueprint of how the research is conducted. He further explains that a research design focuses on the end product, formulates a research problem as a point of departure, and focuses on the logic of research.

\section{Research Method}

Methodology is systematic enquiry into the world and is practical in nature. It is concerned with the specific ways used to 
understand the world better (Henning, 2004). As De Vos (2007:358) explains, a research methodology is a diligent and systematic enquiry of a phenomenon to discover or revise facts and theories by applying different methods and guidelines to enable researchers to make broad and accurate generalizations.

Quantitative method involves evaluation of various strategies such as ethnography, naturalistic enquiry, close study, field study and participation observation (Maree, 2010:385). The quantitative researcher tests theories about reality, looks for cause and effect and uses quantitative measures to gather data to test hypotheses. It is descriptive, explanatory and leads to the discovery of new knowledge.

Qualitative approach, on the other hand, develops a complex, holistic picture, analyses words, and reports detailed views of informants and conducts the study in a natural settings (Creswell 2007).

Milne (2006: 329) extends the meaning in adding that qualitative research focuses on subjective meanings, definitions, metaphors, symbols, and descriptions of specific cases. Against this background, both designs were used in order to generate interpretations on the effects of incentives in teacher recruitment and retention in the North-West Province in South Africa (Milne, 2006: 421).

\subsection{Instruments}

In the empirical investigation of the study, both the self-administered questionnaire and the semi-structured interview schedule were used.

\subsection{Questionnaires}

According to Maree (2010: 157) a questionnaire enables the subjects to respond to questions and is a data-collecting instrument used for surveys. Greenfield (2002:174) avers that reliability, validity, discrimination, response rate, same meaning for all respondents, relevance, exhaustiveness and inclusiveness should be considered when developing questionnaires.

\subsection{Semi- structured interview}

The semi-structured interview was used to corroborate data emerging from other data sources. It seldom spanned a long time period and required the participant to answer a set of predetermined questions as De Vos (2007: 293) suggests.

\subsection{Population}

The population of this study was all the teachers and principals in the 325 schools that received rural allowances from 2008-2012 across the North West province.

\subsection{Sampling}

A sample is a set of individuals selected from a population and intended to represent the population under study. According to Henning (2004) sampling involves the selection of a portion of a population as a representation of the population to ensure that the sample is representative. In this study, a random sampling technique was used and the strata was $163(50) \%$ of population.

\subsection{Data collection and processing}

A circular was written to all the Area Offices (AO) in the Districts to inform them of the study. The sampled schools and teachers were also notified about the study. The Departmental Research Services officials carried out the data collection process over a period of two weeks across the Districts in North-West.

\subsection{Data analysis technique used}

In this study, graphs and tables were used to analyse data. Educational Departmental Research Services officials captured, cleaned and coded data before it was computed. Data cleaning was done to limit the risk of data inaccuracies and invalid conclusions. Coding data, according to Milne (2006: 295), means "systematically reorganizing data that is 
computer readable."

\section{Analysis and Results Reporting from the Quantative Data}

The data has been analysed and graphically presented in accordance with items as reflected in the data collection instrument.

\subsection{Highest educational qualification}

The intention of the item was to find out the highest qualifications that the teachers possess.

The results show that $43 \%$ of the respondents had an Advanced Certificate in Education as their highest qualification. Of the total respondents, $20 \%$ still possessed the University Diploma in Education as their highest qualification. However, it is encouraging to note that $22 \%$ of the participants had an Honours degree. None of the participants had a Masters' degree nor a Doctoral degree.

\subsection{School type}

The Department of Basic Education has directed that schools should be classified into two categories, namely, primary and secondary. The intention of the item was to establish the different schools' types.

Figure 1: Schools by type in North-West Province, $S A(N=100)$

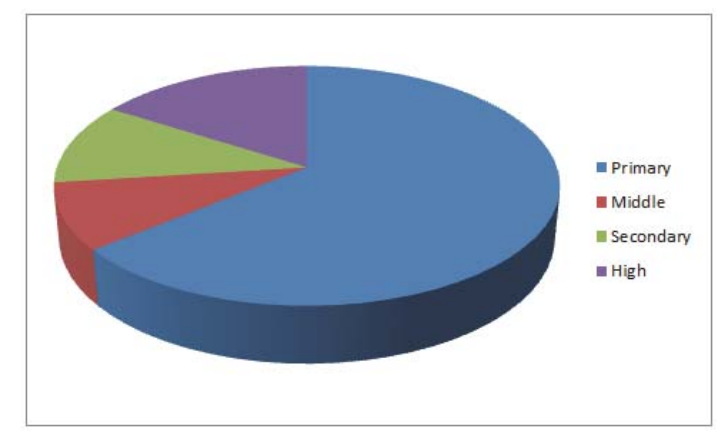

Figure 1 above shows that $64 \%$ of the respondents are teaching at primary schools and $16 \%$ at high schools, about $11 \%$ at secondary schools and $9 \%$ at middle schools. North-West province has therefore more primary schools than secondary.

\subsection{Years of teaching at current school}

The intention of the item was to determine the number of years that a teacher has been at the current school, implying therefore the existence of some reasonable positive orientation or incentive scheme to extend their teaching time in such schools.

Figure 2: Respondents' tenure at current school

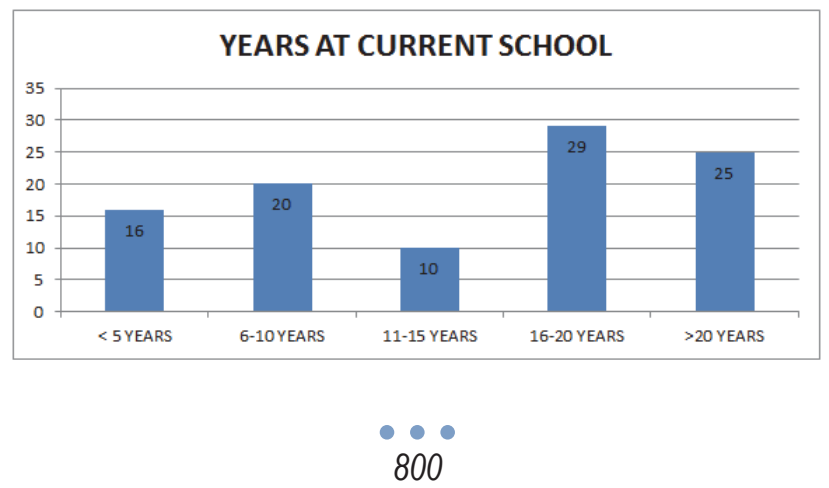


$64 \%$ of the respondents have been teaching at their current schools for more than 10 years and only $16 \%$ have been at their schools for less than 5 years. This suggests a sense of continuity in terms of service.

\subsection{Motivation through the rural allowance}

The intention of the item was to find out if teachers are motivated by TRIS to stay at the school and if they are satisfied with it. Teachers also had to indicate if they transferred to their current school because of the allowance, and, if they would relocate to an urban school given a chance to do that despite receiving the rural allowance here.

Figure 3: The impact of TRIS as a motivational instrument

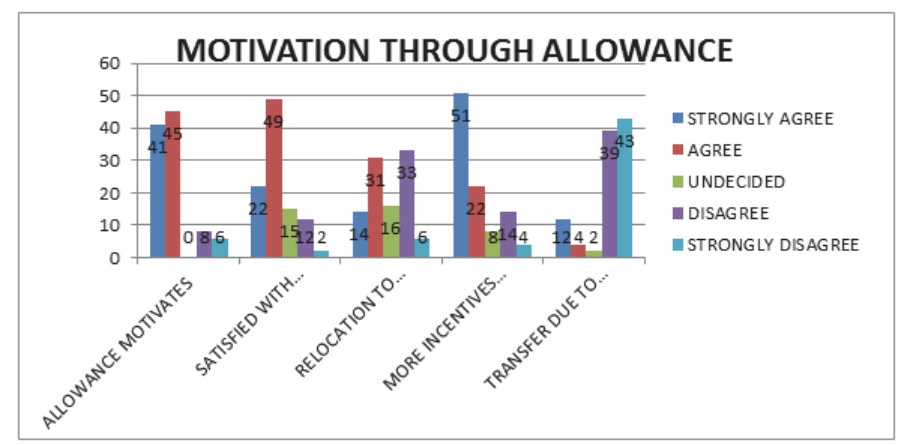

The above figure indicates that $86 \%$ of the respondents agreed that TRIS motivates them to work at their current schools and $71 \%$ are satisfied with it. However, $45 \%$ of the respondents indicated that they would gladly relocate to an urban school given a chance to do that despite receiving the rural allowance currently. Also, important to note is that $39 \%$ of them indicated that they would not relocate to an urban school.

Only $16 \%$ of the respondents transferred to their current schools due to the allowance despite one of its intentions being to lure more teachers to rural schools. $73 \%$ agreed that they needed more incentives for them to continue working in rural schools.

\subsubsection{Class attendance}

One intention of TRIS is to motivate teachers so that they always attend school and their classes on time. The item intended to determine if indeed teachers always attended to their classes on time when at school.

Figure 4: TRIS as incentivising class attendance by teachers

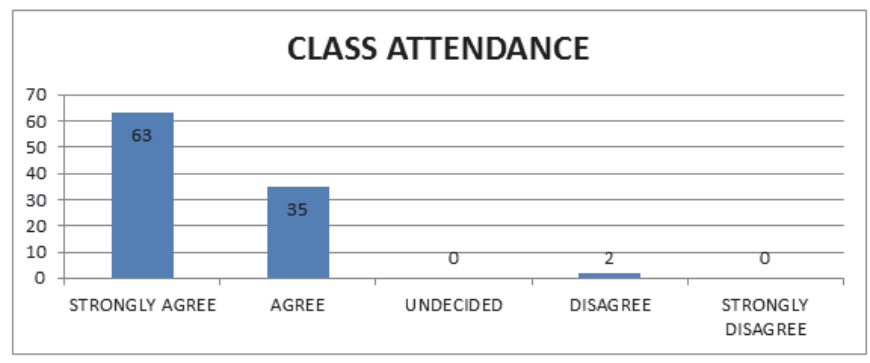

Figure 4 indicates that $98 \%$ of the respondents agreed that they always attend to their classes on time when at school. It is worrying to note that $2 \%$ disagreed to say they do not attend to their classes on time.

\subsection{Working conditions}

It is the responsibility of the Department of Basic Education to provide schools with basic resources and to ensure that 
the environment is conducive for effective teaching and learning. The item needed teachers to indicate whether they experience unfavourable working conditions due to the rurality of their schools which often cause them to be absent and also whether there are basic resources for effective teaching and learning to take place.

Figure 5: Working conditions as factor in teacher presence at work

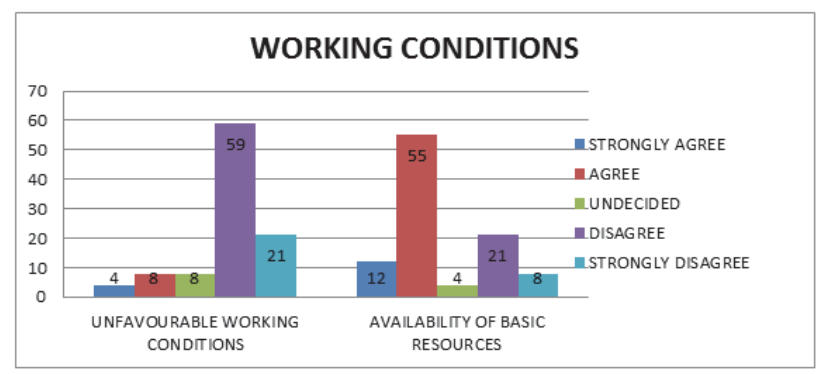

Figure 5 indicates that $80 \%$ of the respondents disagreed that they experienced unfavourable working conditions which often cause them to be absent. Only $12 \%$ of respondents agreed that they experienced unfavourable conditions at their schools. It is also emerged that $67 \%$ of respondents agreed that they had basic resources required for effective teaching and learning to take place whereas $29 \%$ disagreed.

Item 11 of the questionnaire asked teachers to indicate whether learners' performance had improved since they started receiving rural allowance, also indicate if learners are committed to their studies and show enthusiasm.

Figure 6: TRIS and its perceived influence on learner performance

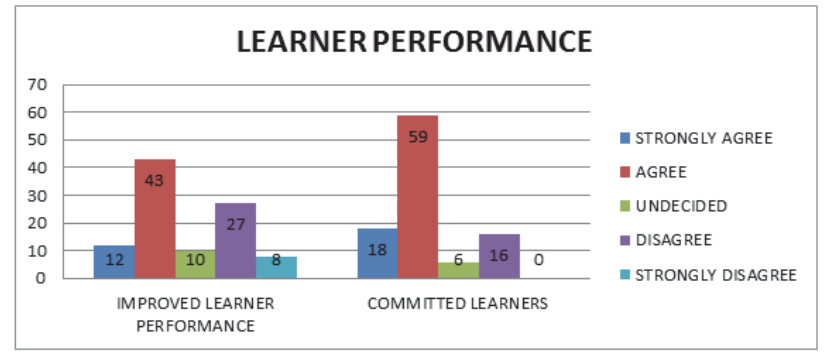

The above figure shows that only $55 \%$ of the respondents agreed that their learners' performance have improved since they started receiving rural allowance and $35 \%$ of them disagreed. It is also indicated that $77 \%$ of respondents agreed that their learners are more committed to their studies and $16 \%$ disagreed with that.

Document analysis was conducted during data collection process whereby scrutiny of learners' results was done for all grades from 2009 to 2012. The item intended to find if there is an improvement in subject performance after teachers started to receive rural allowance.

\section{Figure 7}

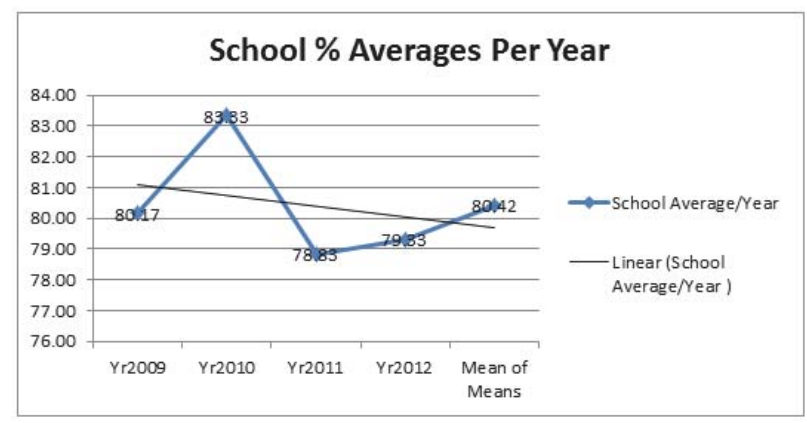


Figure 7 indicates a downward trendline of performance after the introduction of the TRIS. This is despite the 3 percentage points increase in 2010. The overall school percentage average in the four year period after the introduction of TRIS is at 80.42 , not significantly above the first year school average when the scheme was instroduced. This should mean, against the perceptions of the respondents, the system is not impacting positively.

\section{Issues Related to Rural Allowance}

The respondents were asked to indicate any other issues related to rural allowance that they thought had to be attended to. These are some of the responses made by majority of them:

- Rural allowance must be aligned with the inflation as it is used for travelling.

- The method used to determine the remoteness of the school should be revisited and corrected.

- TRIS should be paid monthly like housing allowance.

- The department should speed up the process of payment.

- TRIS should be consistent and continuous as it is sometimes not paid for the whole year.

- The rural incentive scale should be revised.

Qualifications and subjects taught should be considered when making payments for rural allowance.

\section{Analysis and Results Reporting of Data from the Principals' Instrument}

A semi- structured interview was conducted with principals of schools receiving TRIS to source their views on the impact of the allowance in terms of teacher retention, teacher recruitment and learner performance .

Item 15 of the questionnaire sought to determine if the schools managed to retain and recruit more qualified teachers since the introduction of TRIS.

\section{Figure 8}

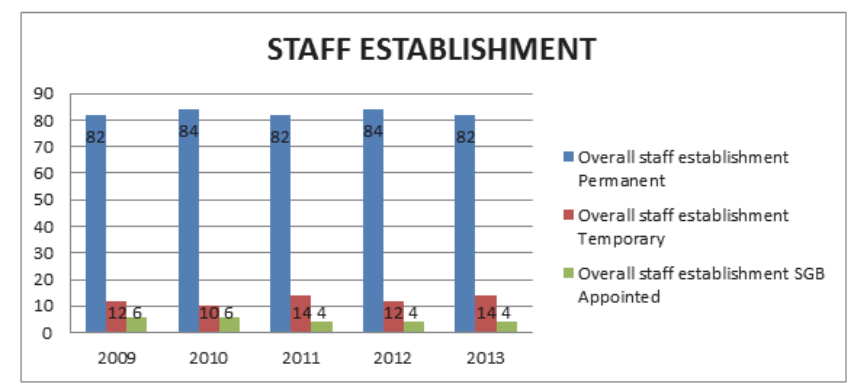

Figure 8 above shows that more than $80 \%$ of the schools had permanently employed staff members across the five year period. It is encouraging to note that the department is taking provision of human resource at rural schools seriously.

Item 16 of the questionnaire sought to determine if the schools managed to retain and enrol more learners since the introduction of rural allowance.

\section{Figure 9}

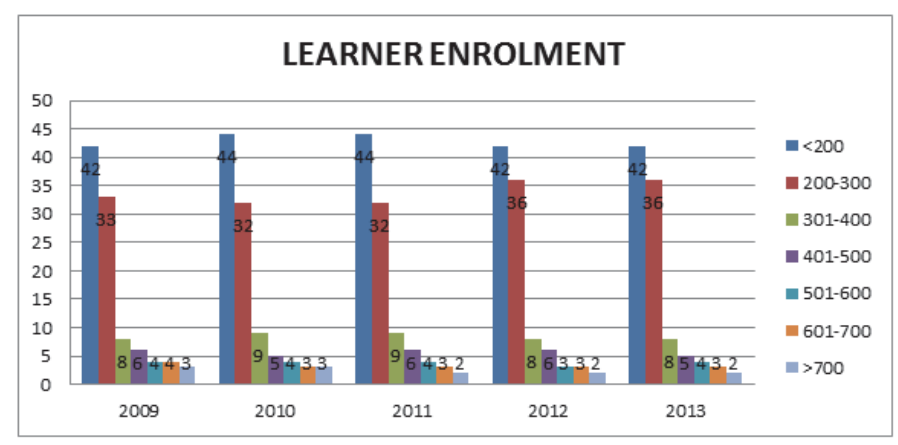


The above indicates that majority (above 70\%) of the schools have had a learner enrolment below 300 over the past five years. Only $6 \%$ of the sampled schools had learner enrolment of over 700 in 2013.

Item 17 intended to find out from principals whether learners' performance has improved since they started receiving TRIS.

\section{Figure 10}

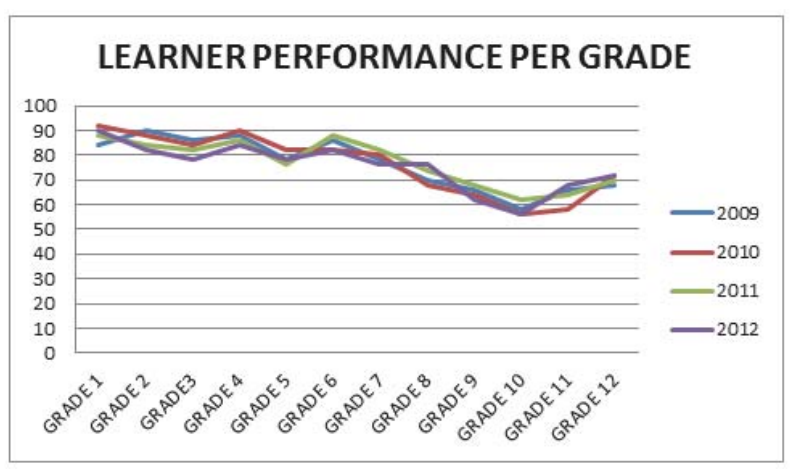

The above figure indicates that learner performance in the lower grades is good (above 70\%) as compared to performance in higher grades. The figure further reveals that there is a slight improvement in 2011 but only evident from grade 6 to grade 10. Grade 10 proves to be the lowest performing grade with an average of $58 \%$ across the years.

Item 18 sought to find out if principals thought that they have managed to retain teachers at their respective schools since the introduction of rural allowance. $70 \%$ indicated that they have received rural allowance for only two years hence they could not make a decisive conclusion.

Most of the respondents mentioned the following as the most pertinent issues regarding teacher retention:

- TRIS managed to retain some teachers but due to delay and inconsistent payment, some teachers have left.

- The teachers retained indicated that they would not go to urban areas unless through promotion.

- The request for transfer is minimal since the inception of rural inceptives.

One of the intentions of rural allowance is to attract more qualified teachers to rural schools. The intention of item 19 was to determine the extent to which this has been achieved. $86 \%$ indicated that a number of applications have been received at the school but could not recommend any one due to PPM limitations.

Some of the comments highlighted were the following:

- Principals struggled to recruit teachers and resorted to temporarily employing foreigners.

- First rural allowance payment was received in 2012 therefore no assessment could be made on that basis.

Item 20 intended to find if there was an improvement in learner performance after teachers received rural allowance. 60\% indicated that learner performance has improved over the years, but stressed that it was not because of rural allowance.

Some of the comments highlighted are the following:

- Teachers are highly motivated by the incentive and their high morale could be translated into better learner performance.

- The allowance served as a motivating factor to teachers.

- The staff has been the same and rural incentives was received once and therefore could not say that rural incentives played any role in learner performance.

- Learner performance is fluctuating

- Allowance was only paid in 2011 so assessment could not be made on this basis.

Item 22 asked respondents if they had enough resources for effective teaching and learning to take place and 46\% of respondents agreed that they have enough resources.

Some of the comments highlighted the following:

- PPM stifles human resource allocation hence curriculum delivery is compromised

- There is a need for a proper laboratory, furniture and library in rural schools

- There is a is shortage of textbooks, hence the need for top up 
- Learners could not access e-learning resources

- Department of Education ought to supply Science, Technology and Mathematics kits for practical demonstrations

- The problem of multigrade teaching remains a sore presence in rural schools

On the question of whether or not the curriculum in place catered for the needs of teachers and learners at rural schools, only $52 \%$ of the respondents agreed that the curriculum in place caters for the needs of teachers and learners at rural schools.

Some of the comments highlighted the following:

- Multi grade teaching is still experienced and not catered for by the curriculum

- Curriculum bridges the gap between the rural experiences learners are accustomed to and the urban experiences they are not familiar with

- Curriculum should include agriculture since most rural learners are familiar with it

- CAPS curriculum is simplified in such a way that teachers get it easy to teach learners

- Rural and needy learners are not exposed to technological resources

- The ever changing approach to curriculum is a challenge

- Most of the subject content is too abstract for learners in rural areas

\section{Major Findings of the Article}

- Majority of the participants are not satisfied with the way rural allowance is calculated and the fact that the allowance is paid only once per year

- More incentives like car allowance, accommodation and laptops are needed by teachers in rural schools

- Rural allowance has not significantly assisted to retain and recruit teachers to rural schools

- Most of the participants do not link the improved teacher and learner performance to rural allowance

- Teachers at rural schools are overloaded due to PPM and multigrade teaching is practiced

- Curriculum does not take into consideration contextual factors experienced in rural schools

- Learner enrolment has declined in most of the schools

\section{Discussion}

The report's major recommendations are that:

- DoE should continue to pay rural allowance but do it on a consistent monthly basis

- Scale and method used to calculate the allowance should be revised

- All teachers in rural schools, irrespective of their status, should be incentivized

- Post provisioning model (PPM) should be reviewed since it disadvantages rural schools and deprives learners of quality education

- All teachers be trained on multigrade teaching

\section{In Closing}

The policy on rural allowance by the Department of Basic Education remains relevant only if it attains what it aims to achieve, especially for a developing economy such as South Africa. Although the monetary allowance paid to teachers might not be the only incentive they need, it is viewed as a good start to address the issue of rural education to ensure that every child's right to quality education is upheld. The retention of teachers by rural schools, low teacher absenteeism, high teacher morale, and, the improved learner performance attest to the relevance of the allowance. It remains the sole responsibility of the department to ensure that all the targeted beneficiaries are incentivized accordingly.

\section{References}

Babbie, E., Mouton, J., Vorster, P. \& Prozesky, B. (2006). The Practice of Social Research. Cape Town: Oxford University Press.

Bärnighausen, T. and Bloom, D. (2009) Financial incentives for return of service in underserved areas: A systematic review. BMC Health Services Research 9: article 86

Bless, C. \& Higson-Smith, C. (2000).Fundamentals of Social Research Methods. (3rd ed.) Kenwyn, Juta. 
Cooper, D.R. and Schindler, P.S. (2003). Business Research Methods. $8^{\text {th }}$ Edition. New York: McGraw Hill.

Cozby, P.C. 2004. Methods in Behavioural Research. Eighth Edition: McGraw-Hill.

National Education Infrastructure Management System: National Assessment Report (2007) Department of Education, Government Printers, Pretoria.

David Monk (2007) Recruiting and Retaining High-Quality Teachers in rural areas: Excellence in the Classroom Journal Issue 1 Volume 17

David Featherman (2007) The Next Twenty-Five Years: Affirmative Action in Higher Education in the United States and South Africa. University of Michigan Press.

De Vos, A.S., Strydom, H., Fouché, C.B. \& Delport, C.S.L. 2008. Research at grass roots. (3 $\left.{ }^{\text {rd }}\right)$. Pretoria: Van Schaik Publishers

Department of Education: Report on the methodology used to classify towns in South Africa and calculating distances between schools and their nearest towns (2007).Government Printers, Pretoria.

Ditlopo, P. and Blaauw, D. (2010) The impact of human resource interventions on the motivation and retention of health professionals in South Africa. Johannesburg: Centre for Health Policy, School of Public Health, University of Witwatersrand, Johannesburg.

Dunn, D.S. 2001. Statistics and Data Analysis for the Behavioural Science. New York: McGraw-Hill. http://www.education.gov.zal LinkClick.aspx?fileticket=VlqIdHT7qZ8\%3D\&tabid=93\&mid=1952 Education Statistics in South Africa 2010, Published by the Department of Basic Education, February 2012

McMillan, J.H. and Schumacher, S., (2001), Research and Education: A conceptual Introduction, (3rd), Haper Collins Publishers, Virginia Commonwealth University.

Mouton, J. (2002). How to succeed in your Master's and Doctoral Studies. (3rd ed.). Pretoria, Van Schaik Publishers.

Sedibe M. (2006). A comparative study into variables contributing towards establishing a learning culture in schools. University of Pretoria

Statistics South Africa. (2010) Mid-year Population Estimates Pretoria: Statistics South Africa. Report No. P0302. 